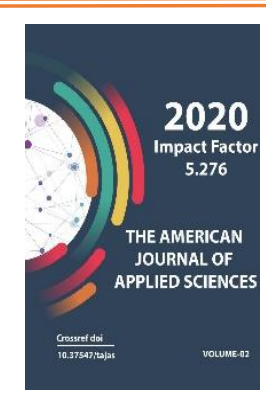

Copyright: Original content from this work may be used under the terms of the creative commons attributes 4.0 licence.

\section{Healthy Lifestyle And Safety Activity}

Muratova Gulsara Saidovna

Lecturers Of The Faculty Of Natural Sciences, Bukhara State University, Uzbekistan

Sharofutdinova Rumiya Infarovna

Lecturers Of The Faculty Of Natural Sciences, Bukhara State University, Uzbekistan

Asadullaev Anvar Narzullaevich

Lecturers Of The Faculty Of Natural Sciences, Bukhara State University, Uzbekistan

\title{
ABSTRACT
}

This article defines the concept of a healthy lifestyle based on anonymous questioning for the purpose of identification of number of the students who go in for sports and the ways of motivating students to have a healthy lifestyle.

\section{KEYWORDS}

Healthy lifestyle, health, sports activities, physical culture

\section{INTRODUCTION}

Human health is one of the vital and global problems where there is the greatest aggravation of the contradictions generated by current and expected future situations, where disproportionate conditions and achievements can achieve catastrophic consequences in the foreseeable future. Health, as they say, is not the absence of disease, but the physical, social, psychological harmony of a person. We, the people of the twenty-first century, have completely forgotten how it is to take care of our health, but a healthy lifestyle helps to successfully fulfill our plans, realize goals and objectives, and cope with difficulties. Good health, strengthened by the person himself, will allow him to live a long and full of joys life. Health is an invaluable wealth of each individual, and of the whole society as a whole, it reduces the likelihood of various diseases and increases 
the life expectancy of a person. The safety of a person's life is his skill in everyday life recognizes and anticipate a hazard in order to avoid or minimize it its consequences. The safety of a person's life is such a state of his body during life when the action of external and internal factors does not lead to death or diseases and does not interfere with the achievement of certain desirable for human goals. The safety of human life is the study of the problem of dangers, threatening a person, society, state, the whole world, and the development appropriate methods of protection against them. The solution to the problem of life safety is to provide comfortable living conditions for people, in protecting a person from the effects of harmful environmental factors exceeding the normative - permissible levels. Ensuring the safety of work and rest of a person contributes to an increase the duration of his life, the preservation of his mental and physical health.

\section{MATERIALS AND METHODS}

Today, the study of the safety of human life is based on the conscious need of society to warn against dangers rules of safe behavior of the state and its inhabitants, as well as compliance with the laws prescribed in the constitution of the Republic of Uzbekistan. A feature of the study of the safety of human life is that it cannot be investigated by the methods of particular sciences or by simply summing them methods. It covers a whole spectrum of sciences that rely on absolutely different aspects of life. Throughout its development, humanity has been constantly faced with security issue. Through the progress that changed the world the wellbeing of people has increased, the quality of life and their working conditions have improved, the production of industry and agriculture has reached unprecedented proportions economy, especially in economically developed countries. The destructive effect of many technologies and chemicals has increased; there were huge human losses and economic damage. The safety of every person and the environment must be considered taking into account all economic, social and environmental consequences. And we can say that security today should become part of the lifestyle of each individual. We interpret a healthy lifestyle as behavior aimed at the rational satisfaction of biological and social needs. A healthy lifestyle can also be defined as the most characteristic, typical activity in specific socio-economic, political, environmental and other conditions, aimed at preserving, improving and strengthening people's health. This concept includes, on the one hand, the formation of positive behavior, and on the other, overcoming health risk factors [1]. We set the following tasks:

1. Reveal how many students have bad habits.

2. Find out how many students are involved in sports.

3. Offer options for introducing students to a healthy lifestyle.

We conducted an anonymous survey among students of our university aged 18-25. More than 100 people were interviewed. The questionnaire contained the following questions.

1. Do you go in for sports / exercise?

2. If so, how?

3. Do you smoke?

4. If so, how long ago?

5. How old are you?

\section{RESULTS AND DISCUSSIONS}

The results of the survey are as follows: 68 people gave a positive answer to the first question. Of these, 31 go to the gym, 7 are engaged in volleyball, 3 - basketball, 12 people go regularly to the skating rink, 15 people are various other types of outdoor activities. 
40 out of 100 people smoke. The age of the respondents is $18-19$ years old - 41, 20-21 years old - 32 students, 22-23 years old - 15 people, 24 years old - 12 people. Based on the results obtained, the following conclusions were drawn: $38 \%$ of the respondents did not attach much importance to physical education. More than $50 \%$ of students have such a bad habit as smoking. Therefore, it is necessary to motivate young people to lead a healthy lifestyle. We want to suggest the following methods.

1. To hold more often competitions between groups, faculties, courses in various sports.

2. Coupons for ice cream, pizza and other fast food are sometimes given as prizes. Instead, you can donate gym, fitness, and so on.

3. Carries out actions near the university, for example: exchange a pack of cigarettes for chocolate.

The formation of motivation for a healthy lifestyle should start from infancy and continue throughout the entire learning process. For this, it is necessary to use various techniques, taking into account the age status, as well as the level of physical and psychological fitness. And in a preschool educational institution, and in a secondary school, and in a university, it is necessary to constantly develop and maintain a person's motivation for physical self-improvement, taking care of their health. To maintain a healthy lifestyle, it is necessary to teach the population how to act in emergency situations in peacetime and wartime, to teach the basics of safe human behavior in everyday life, as well as in emergency situations of a natural, technogenic and social nature. For this reason, the course "Life Safety" is being taught in universities nowadays in our country. This allows employees of the education system to shape the health of the younger generation and the population as a whole [2].
In conclusion, we can say that among the most important ways of developing scientific research in the field of life safety, we should note that the need to improve and increase the level of human health by drawing up a certain schedule of work on oneself. Not everyone can immediately take up dramatic improvement in health. In this case, we can start implementing the program gradually, for example, start with morning exercises, and then supplement it with jogging. Then you can do the fight against excess weight. The goal should be achieved not by extraordinary measures, but again gradually, not to allow the use of alcohol by young people. Our health is in our own hands. Especially, we must understand that only healthy people can survive in current global pandemic Covid 19 so that we protect ourselves against the viruses.

\section{REFERENCES}

1. Nazarova E.N, Zhilov Yu. D. Fundamentals of a healthy lifestyle. M.: Academy, 2013.

2. Ochilova N.R, Muratova G.S, Sharafuddinova R.I, Manual for university students "Safety of life activities" T.:2009

3. Lutovina E.E. Forming a culture of life safety of schoolchildren in the modern educational space / E.E. Lutovina, I.A. Novikov // Pedagogy: family -schoolsociety: monograph / under total. ed. O.I. Kirikov. - Voronezh: VGPU, 2014.Vol. 32.

4. Matchin A.A. Healthy lifestyle and its components: studies. Manual / G.A. Matchin Orenburg: Publishing house of the OGPU, 2013

5. Yusupovich, K. S. (2020). The Emergence Of Religious Views Is Exemplified By The Southern Regions. The American Journal of Social Science and Education Innovations, 2(10), 143145. 